\title{
2.4 Communication as the Main Characteristic of Life
}

\author{
Guenther Witzany
}

\section{CONTENTS}

2.4.1 Introduction.

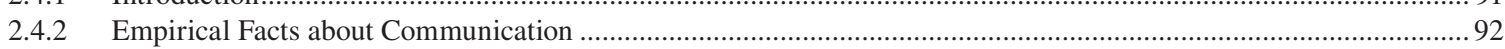

2.4.2.1 Communication is Social Interaction ……................................................................................... 92

2.4.2.2 Communication is Sign-Mediated According to Rules ....................................................................... 92

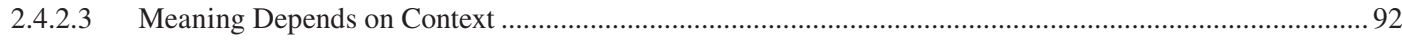

2.4.2.4 Communication Initiates De Novo Generation ................................................................................. 92

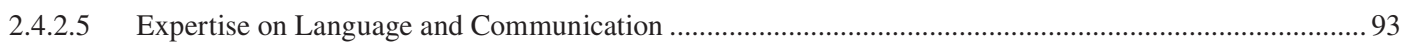

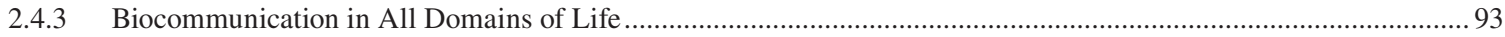

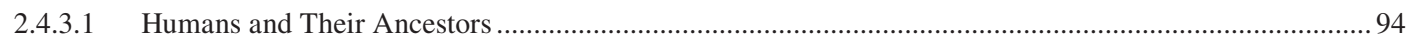

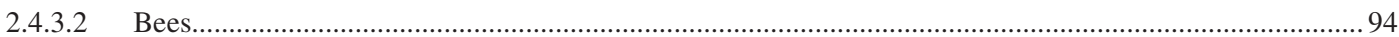

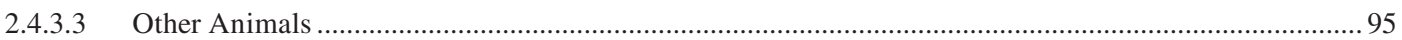

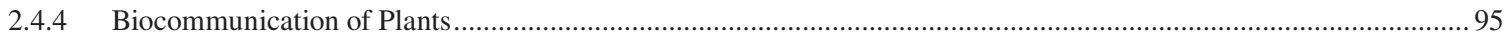

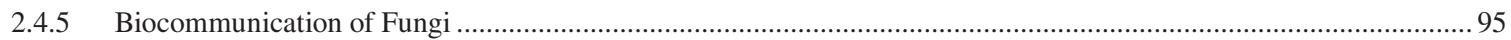

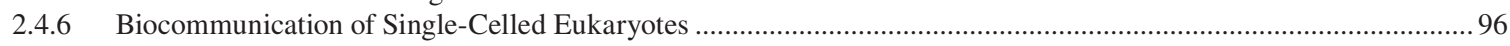

2.4.7 Biocommunication of Akaryotes (Bacteria and Archaea) …........................................................................... 96

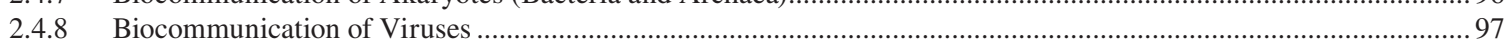

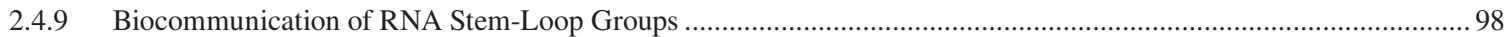

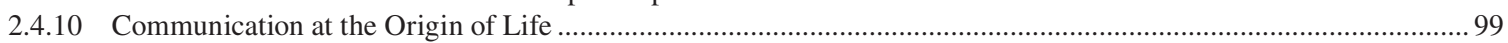

2.4.10.1 From "Dead" to "Living" by Social Interacting RNAs........................................................................... 99

2.4.10.2 The Origin of RNA Group Identity and the Origin as a Genetic Code ................................................... 99

2.4.10.3 Repetitive Sequence Syntax is Essential in RNA Communication..................................................... 100

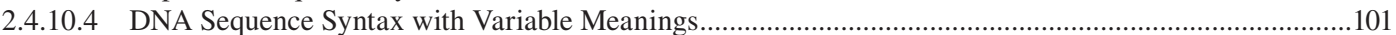

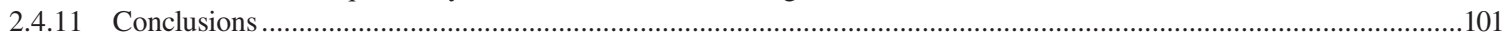

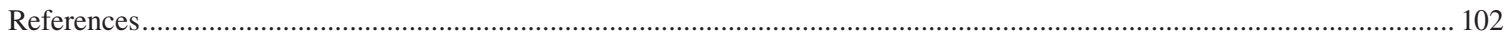

\subsubsection{INTRODUCTION}

With an expertise in the philosophies of science and language, I turned my focus to the philosophy of biology and life sciences in the mid-1980s. I found it interesting that the results of the philosophy of science debates did not reach any biological discipline, although philosophy of science is the essential discipline for the foundations and justifications of scientific theory building and methodology. At the center of these more than half a century

AQ 1 lasting debates: After 2000 years of metaphysical theories and concepts, in the early twentieth century, a group of empiricists wanted to establish "exact science" by using strictly "scientific" sentences and clearly delimitate scientific research and knowledge from non-scientific sentences of metaphysics, theology, or poetry. "Scientific" meant empirically based, experimentally testable, and theoretically formalizable, because mathematics was assumed to be the only exact science that could depict material (physical and chemical) reality (Whitehead and Russel 1910-1913; Goedel 1931; Carnap 1939).
The crucial question remained how to construct sentences that are scientific and not metaphysical, that is, the question how to define language, the ultimate prerequisite of any human utterance. The debate lasted from 1920 to 1980, with its most prominent proponents such as early Wittgenstein, Carnap, Hilbert, Russel, Whitehead, Goedel, Shannon, Weaver, Turing, von Neumann, late Wittgenstein, Austin, Searle, Chomsky, and Habermas (Witzany 2010). The results of these debates are part of the history of science:

- The concept of a coherent axiomatic system with error-free logical sentences is impossible, in principle.

- The concept of an exact scientific language was a pipe dream.

- Natural languages do not speak themselves; there are always real-life individuals in populations that generate and use such languages to coordinate and organize the real-life world, and the usage of natural 
languages is, therefore, part of communication, that is, a kind of social interaction.

- Living agents that use natural languages are principally able to generate new sign sequences that cannot be predicted or deduced from former ones and for which no algorithm is available, in principle.

- The meaning (semantics) of the signs and sign sequences in natural languages depends on the reallife context (pragmatics) within which signs are used and not on its syntax.

As a consequence, formalizable, that is, mathematical, theories of (context-free) languages are not an appropriate tool for explaining the essential features of natural languages used in communication processes. They cannot identify the context dependence of meaning and its deep grammar that helps to transport different and even contradictory meanings to the superficial grammar, both represented by identical sign sequences. Additionally, describing the social character of real-life organisms is not within their expertise, because social interacting organisms don't behave like formalizable abiotic elements, and, for the inherent feature of generating new sequences, new behavior, and new interactional motifs, no algorithm is available in principle (Witzany 1995, 2010,

AQ 2 2011). As we will see at the end of this contribution, this must have serious consequences in the explanatory model on how to describe the sign-mediated interactions in non-cellular early RNA-world and emergence of the genetic code, genetic

AQ 3 information, and its regulation.

\subsubsection{EMPIRICAL FACTS ABOUT COMMUNICATION}

\subsubsection{Communication is Social Interaction}

Communication designates social interaction. Social interacting living agents need some tools so that interaction may lead to coordination and organization of common behavior to reach goals. In contrast to physical-chemical interactions on an abiotic planet, communicative interactions on biotic

AQ 4 planets are mediated by signs. Such signs must be uttered by bodily expressed movements, phonetics, audiovisuality, tactility (e.g., vibrational), or odor (semiochemical). This means that sign-mediated utterances may also be transported as body movement patterns (e.g., series of gestures).

The use of signs in communicative interactions must be learned somehow (Morris 1946). This means that the use must follow an acquired competence. The competence of living agents is inherited or learned or both. In any case, it needs some social interaction experience to trigger this competence into an actual available behavior. In concrete real-life social experiences, living agents learn to designate a message for non-self agents in a real-life context. In social experiences, living agents learn to use more than one sign and combine multiple different signs into sign sequences to communicate complex content. Social experiences are the essential background to learning contextual, combinatorial, and contentual rules on how to use signs in social interactions (Witzany 2000).

\subsubsection{Communication is Sign-Mediated According to Rules}

Communication is a kind of social interaction. It is an empirically proven fact that communication could not be invented by a singular living agent for one time only once. Communication needs signs to communicate context-relevant content. Such signs can be combined in a line-up to sign sequences. The use of signs needs some competence to combine sign sequences correctly. This competence of rule-following depends on social interaction experience (context). Communication is the essential interaction to common understanding of content (meaning). Social interaction experience is embedded into a cultural background history.

\subsubsection{Meaning Depends on Context}

The meaning of a sign sequence or a "word" or any other sign used to communicate is a social function (Mead 1934). The behavioral reaction to a communicative utterance emerges semantic meaning. Not to forget that natural communication depends on the context. Also, meaning-generating social events are context-dependent. For example, the humble dance in bees gives direction and energy costs in food gathering. Exactly the same dance figures are used during the hive search, where context transports the completely different meaning of an appropriate hive (Witzany 2012). Another example: The sentence "Shooting of the hunters" in human communication may transmit the message that hunters shoot and, conversely, that hunters are shot. Without context, contradictory semantics of sign sequences cannot be identified. Syntactic analyses alone are insufficient to identify semantic content (Baluska and Witzany 2012).

\subsubsection{Communication Initiates De Novo Generation}

Communication as rule-governed sign-mediated interactions are different from interactions in a purely physical-chemical world without any biotic agents. In such interactions, signs and rules of sign use as well as sign-using living agents are not existent. In contrast, communicating living agents share a limited repertoire of signs that are used according to a limited number of rules that must be followed to generate correct sign sequences to designate context-dependent content. Most interesting is the fact that such rules-although rather conservative-may be changed in extreme cases or if adaptation is necessary. Rule-following by living agents is rather flexible in contrast to natural laws to which living agents abide strictly. This means that communication is the essential tool to generate new signs, sign sequences, new rules for sign use, and generation of new content according to unexpected contextual circumstances (Witzany 2015). Communicating 
living agents are able, in principle, to generate new communicative patterns for better or innovative adaptation to a new and unforeseeable situation.

\subsubsection{EXPERTISE ON LANGUAGE AND Communication}

Curiously, many biologists are not very familiar with the current definitions of "language" and "communication," although they are commonly used in molecular biology to speak about "genetic code," "code without commas" (Crick et al. 1957), "nucleic acid language," "recognition sequences," "transcription," "translation," "amino acid language," "immune responses," "intercellular communication," etc. The above-listed theoretical and empirically tested results on "language" and "communication" have been ignored until today. If we speak now about (1) the three categories of signs (index, icon, and symbol); (2) the three complementary non-reducible levels of semiotic rules' syntax, pragmatics, and semantics; and (3) communication as rule-governed sign-mediated interactions, it can easily be seen that all these categories are nearly unknown in biology, especially in molecular biology, cell biology, genetics, bioinformatics, and related disciplines (Schroedinger 1944; Brenner 2012; Eigen 2013).

All the previously summarized characteristics of communication processes are results of empirical investigations (Habermas 1984, 1987; Austin 1975; Searle 1976; Tomasello 2008). These are no hypotheses or theoretical constructions but empirically proven facts. Some derive from investigations on cognition differences between apes and humans, some from investigations of communicative interactions and speech acts, and some from investigations of language constructions and applications. There is no doubt that language, communication, and social interacting living agents are within the expertise of empirical social sciences.

In the last 100 years, there has been an abundance of theories and concepts on language and communication by natural sciences, such as mathematics, physics, chemistry, information theory, cybernetic systems theory and its derivatives, "mathematical theory of language," "cognitive revolution," and "artificial intelligence"(Wiener 1948; Shannon and Waever 1949; Turing 1950; Chomsky 1964, 1965; von Neumann 1966; Nowak and Krakauer 1999). With the results of pragmatic action theory, all of them have been essentially falsified, because none of them could coherently explain the steps from a single biotic agent to a commonly shared understanding as a prerequisite for common coordination and organizational behavior or "how to make the move from a state of private consciousness to a state of mutual agreement and AQ 7 cooperation" (McCarthy 1984).

In this respect, this contribution will demonstrate that communication is the main characteristic not only of humans but also of life generally, based on a common methodological assumption of natural sciences and social sciences by presenting empirical data that can be proved by experiments and observations.

\subsubsection{BIOCOMMUNICATION IN ALL DOMAINS OF LIFE}

If communication is the main characteristic of life, it must be possible to identify communicative actions throughout all domains of life. Until the middle of the last century, language and communication were thought be special tools of only humans. Meanwhile, we know an abundance of examples of non-human languages and communication processes.

Therefore, the description of communication processes must be valid in principle in all organisms, from the simplest akaryote up to the humans. Whereas we identified main characteristics of communication, its (1) social character, (2) dependence on signs according, (3) the three kinds of rules (combinatorial, context-specific, and content-coherent), we must draw our attention from the decades-long narrative suggested by information theory and systems theory, that is, the sender-receiver narrative (coding-decoding), which was wrong in several aspects, as outlined elsewhere (Witzany 1995). Communication is not only an information-transfer process but more than this interaction, mediated mainly by utterances represented by signs. If we speak, or any other organism uses signs to signal something (!), we do something (Austin 1975; Searle 1976).

Interactions between living organisms that are based on signs (signals, icons, and symbols) used according to combinatorial, context-dependent, and content-coherent rules are the very fundamental techniques to coordinate any common behavior and organize division of labor. Although the lifeworld of organisms is rather restricted to their speciesspecific habitats, symbiotic partners, geologically determined niche constructions, the signals they share, and the behavioral motifs they like to use, we can find communication in all organisms of all domains of life (Witzany 2011c, 2012a, 2014a, 2016, 2017a) (Figure 2.4.1).

But biocommunication is not restricted to a speciesspecific lifeworld. Additionally, we must think of cell-cell communication processes in parallel within the organismal bodies, between tissues and organs, to coordinate interactions of the whole body. Last but not least, from the organisms that communicate within their body and between the same or related members of their species, we can also find communication processes between non-related organisms, as in attack

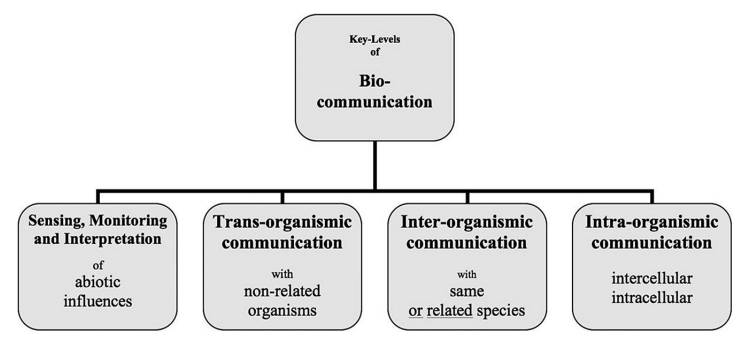

FIGURE 2.4.1 The biocommunication approach identified four levels in which cellular organisms are involved since the start of their life until death. 
and defense behaviors or more than this in an abundance of symbiotic and symbiogenetic interactions (Witzany 2006).

\subsubsection{Humans ANd Their ANCEStors}

To learn a natural language means to communicate basic everyday needs with community members. This is how we learn what a word means. "The meaning of a word is its use" (Wittgenstein 1953), or Ch. S. Peirce: to identify "...meaning, we have, therefore, simply to determine what habits it produces" (Peirce 1923). We can understand words and their sequences, because we have learned a practice of interaction, which includes learning from the community as to which words are combined with which customs or interactional patterns.

Although great apes understand many aspects of social interactions in their lifeworlds, including causal and intentional relationships, there is a crucial difference from human understanding: In contrast even with human infants, great apes cannot participate in shared intentionality or cooperative communication (Tomasello 2008; Bohn et al. 2016; Engelmann et al. 2017).

Another crucial difference between humans and great apes is that humans designate situations and entities for other people in a language-like manner. These other persons then try to understand why active agents wants to share information and why they want them to know this could be relevant to them. Besides the ability to participate in shared intentionality, this requires a variety of complex and recursive logical conclusions about the intentions of others.

The empirical result is that although several animal species can represent situations and other entities cognitively in an abstract way, only humans can generate actively distinct perspectives of the same situation. Additionally, only humans draw social recursive conclusions that are self-reflexive also with regard to the intentional states of others. Also, several animal species evaluate and feed back their actions in respect of their intentional goals, but only humans evaluate their behavior with respect to the normative perspectives of others or their group identity.

The individual intentionality changed into co-operation by means of a common intentionality, which made new forms of cognitive representation, that is, perspectivistic and symbolic, possible. The conclusions changed into social recursive ones, which means they focused not on individual perspectives but on the perspective of all group members.

This new form of co-operation within common intentionality emerged from common goals (not individual ones) and commonly shared attention. These are the ingredients of social coordination, which is different from individual coordination with each other. Group hunting in great apes is characterized by the fact that each individual ape tries to catch the prey. This means the group behavior remains in the "egostatus" for every individual. But the so-called co-operative turn in humans means that the group members now act in a group perspective without "ego-status." The decisions that are taken focus on group benefit, not individual benefit. This was the result of experiments with 3-year-old children, in contrast to great apes, which remain in the "ego-status," although they act together in groups. The children co-operated in several experimental setups, and it was shown that the common goal is so important that individual children who reached their goals early did not stop their actions until all the others had reached their goals. Similar behavior could not be observed in great apes (Tomasello 2008; Bohn et al. 2016; Engelmann et al. 2017).

Additionally, humans communicate with others about content that is not actually present. This means language must serve as symbolic (conventionally derived) representation of information that is not actual but abstract. This is a crucial difference from their ancestors (Bohn et al. 2015).

The speech acts in humans differ fundamentally from their evolutionary ancestors. We can differentiate superficial grammar and deep grammar in human speech acts, or, in the words of John Searle, the founder of speech act theory, we can find locutionary acts done by utterances (designated by their grammatic-semantic sequence); illocutionary acts (what we want to do with what we say), which cannot be identified through analyses of the words that are said but depend on mutual expectations, intentions, emotions, roles, etc.; and the performative speech acts that are characterized by what is done by the one who is addressee of what is said. Especially the illocutionary speech act is nothing that can be identified easily in great apes. Also, in humans, there is no algorithm available to identify such crucial determinants of what is expected and intended. So, natural human communication in everyday life and colloquial speech are nothing that can be computed or predicted easily.

Natural signs used by humans are not only auditory and visual (gestures) but also body movements and tactile. Beyond conscious sign generation, there are inherent unconscious messages transported, as in all other animals by semiochemicals, that is, pheromone and other hormone-like odors, although odor receptors and related tissues are largely lost during retroviral infection events in the African primate populations prior to the chimpanzee-human split (Villarreal 2009). This caused a strong selective pressure to evolve alternative communication tools to perpetuate social life and social order without pre-dominant odor determinants. Additionally, we must not forget that $95 \%$ of the human assembled body masses are persistent settlers, in most cases, symbionts, as demonstrated on the skin or in the human gut, without which humans cannot survive. Natural signs produced by humans to the symbionts depend on cell-cell communication in tissues and organs.

\subsubsection{BEES}

To take an example for communication as the main characteristic of animal life, we can take any species from this kingdom. More appropriate would be animal species that obviously share a coherent swarm behavior, as represented by some fish, insect, or bird species. I will take bees for example, because, for successful investigation of bee language and communication, Karl von Frisch received the Nobel Prize in 1973. 
If we speak about language and communication, we usually think of humans that talk to each other and communicate to organize common goals and to coordinate common behavior (von Frisch 1965).

But since Karl von Frisch received Nobel Prize for detection and investigation of bee languages and dialects, broader research communities and experts in bee breeding noticed that even non-human social animals might communicate to reach complex behavioral patterns. Since Karl von Frisch's work, it has been evident that the highly complex social behavior of bee swarms is organized and coordinated by sign-mediated interactions, that is, communication. If communication processes are disturbed, they may have fatal consequences for bee colonies, especially if we think of special bees' behavior such as foraging, their search for a new hive, and the semantics of bee dances. As in every other natural language, the same sign sequences may have different meanings in different contexts. This means that bees with a limited repertoire of signs can transport different messages, which trigger different response behaviors, with far-reaching consequences (Witzany 1995).

As in every other natural language, bee languages also differ in habitat-dependent dialects. Small groups may generate specific signs according to niche adaptations, which are not present in other habitats, or similar signs may transport different meanings. For example, when mixing Austrian and Italian bees from certain regions, von Frisch exemplified that a special bee movement pattern (dance) that represents the distance to a nutrition field meant 100 meters for Austrian bees but 500 meters for Italian bees, which led to struggle between both groups, because one group did not find what was designated.

Most interestingly, the language of honey bees in colder hemispheres is the only known non-human language that uses AQ 12 body movements that represent symbolic meaning functions.

Natural signs in bee languages are moving patterns, "dances" of various kinds, and motifs that transport all differentiated messages being relevant for social bee life to the other swarm-members. Besides this, hormonal (semiochemical), tactile, vibrational, and even visual signs are used.

\subsubsection{Other Animals}

Similar to the general categories of biocommunication, communication processes within the animal kingdom have been investigated in chimpanzees, elephants, wolfs, dogs, rodents, mouse, rats, spiders, ants, termites, crows, parrots, birds, salamanders, chelonians, cetaceae, fish, cephalopods such as octopus, corals, nematodes (Witzany 2014a), and many others not listed here. Although the detailed investigations according to the conceptual categories listed previously are missing, they can be expected to be undertaken within next decades.

Natural signs in nearly all animals are generated to coordinate reproduction cycles and social membership roles, as well as in mating, kinship welfare, attack, defense, etc., by semiochemicals, that is, hormones, in combination with auditory, visual, and tactile signs that are rather species-specific.

\subsubsection{BIOCOMMUNICATION OF PLANTS}

Plants have traditionally been viewed as growth automatons. Now, we recognize that the coordination of growth and development in plants is possible only by using signs rather than pure mechanics. Understanding the use of signs in communication processes requires a differentiated perspective (Baluska et al. 2006). Chemical molecules are used as signs. They function as signals, messenger substances, information carriers, and memory medium in solid, liquid, or gaseous form (Baluska and Witzany 2012).

Plants are sessile organisms that actively compete for environmental resources, both above and below the ground (Bais et al. 2004). They assess their surroundings, estimate how much energy they need for particular goals, and then realize the optimum variant. They take measures to control certain environmental resources. They perceive themselves and can distinguish between self and non-self. This capability allows them to protect their territory. They process and evaluate information and then modify their behavior accordingly.

To understand these competences, we will notice that this is possible due to parallel communication processes within the plant (intraorganismic), between same and different plant species (interorganismic), and between plants and non-plants (transorganismic). Intraorganismic communication involves sign-mediated interactions in cells (intracellular) and between cells (intercellular).

Intercellular communication processes are crucial in coordinating growth and development and shape and dynamics. Such communication must function on both the local level and between widely separated plant parts. This allows plants to react in a differentiated manner to its current developmental status and physiological influences. Chemical communication is either vesicular trafficking or cell-cell communication via the plasmodesmata. Moreover, numerous signal molecules are produced in or controlled by the cell walls. Physical communication takes place through airborne, electrical, hydraulic, and mechanical signs (Blande and Glinwood 2016).

Natural signs that enable the communication processes between tissues and cells in plants are incredibly complex and encompass nucleic acids, oligonucleotides, proteins and peptides, minerals, oxidative signals, gases, mechanical signals, electrical signals, fatty acids, oligosaccharides, growth factors, several amino acids, various secondary metabolite products (up until now, 100,000 different metabolites are identified), and simple sugars (Baluska and Witzany 2012).

\subsubsection{BIOCOMMUNICATION OF FUNGI}

The evolutionary forerunners to animals and plants are fungi, which are represented by single as well as multicellular species. Currently, it is estimated that there are at least 1.5 million fungal species, out of which about 300,000 are described in the scientific literature. It is estimated that fungi account for at least one-fourth of the global biomass. As with plants, fungi are sessile organisms that can live for extremely long periods or extend over large areas: one example (Armillaria gallica) 
has been found, which covers as much as 15 ha and has an age of approximately 1500 years (Casselman 2007). Another example (Armillaria ostoyae) covers 900 ha and has an estimated age of 2400 years (Casselman 2007). Higher fungi are modular hyphal organisms in that they reproduce by clona-

AQ 13 tion or are parasexual. They establish interlocking networks. The symbiotic relation to plants, especially in the rhizosphere, is indispensable, because without fungal degradants, plants cannot uptake soluble nutrients (Baluska and Witzany 2012).

Natural signs in fungi are restricted to semiochemicals that are generated and interpreted to coordinate further

AQ 14 reactions. To exemplify such signaling process, we can look at the following examples: (i) Mitogen-activated protein kinase (MAPK) signaling is involved in cell integrity, cell wall construction, pheromones/mating, and osmoregulation (Dohlman and Slessareva 2006; Yu et al. 2008). (ii) Cyclic adenosine monophosphate/protein kinase A (cAMP/PKA) system is involved in fungal development and virulence. (iii) RAS protein is involved in cross-talk between signaling cascades. (iv) Calcium-calmodulin-calcineurin are involved in cell survival under oxidative stress, high temperature, and membrane/cell wall perturbation. (v) Rapamycin is involved in the control of cell growth and proliferation (Fernandes et al. 2005). (vi) Aromatic alcohols such as tryptophol and phenethyl alcohol are used as quorum-sensing molecules. (vii) A variety of volatiles (alcohols, esters, ketones, acids, and lipids) and non-volatile inhibitory compounds (Farnesol and $\mathrm{H}_{2} \mathrm{O}_{2}$ ) (Leeder et al. 2011). To date, 400 different secondary metabolites have been documented. These are known to contain mycotoxins and are used both for defensive and aggressive behaviors.

\subsubsection{BIOCOMMUNICATION OF SINGLE-CELLED EUKARYOTES}

Unicellular eukaryotes represent an own kingdom of life. The crucial difference to their evolutionary forerunners, that is, akaryotes, is their rather complex cellular structure, which includes several parts being absent in akaryotes, such as the nucleus, which contains the genome. The Serial Endosymbiotic Theory successfully explained this evolutionary event (Margulis 2004; Witzany 2006). They evolved signaling to modulate fundamental activities such as acquisition of nutrients and reproduction. They can be found in abundance in aqueous and soil environments; they assess their surroundings, estimate how much energy they need for particular goals, and then realize the optimum variant. They take measures to control certain environmental resources

AQ 15 (Witzany and Nowacki 2016). They perceive themselves and can distinguish between self and non-self. They process and evaluate information and then modify their behavior accordingly. In order to generate an appropriate response behavior, protozoa must be able to not only sense but also interpret and memorize important indices from the abiotic environment and adapt to them accordingly. This is decisive in coordinating growth and development, mating, shape, and dynamics.
Parasitic protozoa cause some of the most severe infectious human diseases worldwide.

Natural signs in unicellular eukaryotes are semiochemicals, such as hormones and secondary metabolites that serve as signs within interactions of various motifs, such as reproduction, mating, feeding, attack, and defense. In this respect, it is important to interconnect semiochemicals with the concrete interactional motif (Luporini et al. 1995, 2006). Identical signals may be used in several interaction motifs with quite different meanings, and this indicates the context dependence of signals. Quite common are hormone receptors. Signaling also includes cAMP in different life-cycle stages, calciummediated adenylyl cyclase (AC) regulation, cyclic nucleotide (guanylyl cyclase) signaling involvement in exflagellation, phosphodiesterases (PDEs), and cyclic-nucleotide-activated protein kinases are essentially conserved in protozoa. $\mathrm{Ca}^{2+}$ signaling pathways and intracellular $\mathrm{Ca}^{2+}$ channels are present in nearly all unicellular eukaryotes.

\subsubsection{BIOCOMMUNICATION OF AKARYOTES (BACTERIA AND ARCHAEA)}

Bacteria and non-related akaryotic archaea have been assumed to be the most primitive organisms and consequently have been investigated as single-cell individuals, determined by mechanistic input-output reactions. Now, this picture has changed. Today, we know that bacteria and archaea are part of a community that interacts in a highly sophisticated manner (Crespi 2001). The production and the exchange of messenger molecules enable unicellular organisms to coordinate their behavior like a multicellular organism (Shapiro 1998; Bassler 1999; Schauder and Bassler 2001; Ben Jacob et al. 2004).

The coordinated community, for example, of oral bacteria in humans, relies on intra- and interspecies communication. This community encompasses ca. 500 different species, some of which co-operate while others compete (Kolenbrander et al. 2002). The complexity of potential interactions in the oral cavity and the number of possibilities reach unimaginable proportions if we assume that each of the 500 bacteria species can regulate its genes in response to host-produced molecules and interact with all other bacteria species (Kolenbrander et al. 2002).

The medium of every bacterial and archaeal coordination is communication, that is, sign-mediated interaction (Dunn and Handelsmann 2002). A wide range of chemical molecules serves as signs through which bacterial and archaeal communities coordinate to reach a "quorum," which is the starting point for decision-making: one of many different behavioral patterns will thereby be organized, such as biofilm organization, bioluminescence, virulence, and sporulation (Sharma et al. 2003). Quorum sensing includes not only chemotaxis but also interpretation, which means that the incoming signs are measured against the background memory of the species colony in their real-life world (Kaiser and Losick 1993; Losick and Kaiser 1997). Interpretation before decisionmaking, coordination, and organization, such as fruiting body 
formation and co-operative hierarchical organization, is context-dependent (Witzany 2017a).

Natural signs in bacterial and archaea communications are semiochemicals involved in producing, releasing, detecting, and responding to small hormone-like molecules termed

AQ 17 autoinducers. AHLs and peptides represent the two major classes of known bacterial cell-cell signaling molecules, AHLs, which are the products of LuxI-type autoinducer synthases, short peptides that often contain chemical modifications, phosphorylation cascades that ultimately impinge on DNA-binding transcription factors responsible for regulation

AQ 18 of target genes (Fuqua et al. 1996). In general, bacteria keep their AHL and peptide quorum-sensing conversations private, by each species of bacteria producing and detecting a unique AHL (AHLs differ in their acyl side-chain moieties), peptide, or combination thereof. Archaea share some molecular biological features with Eukarya that are not found in any bacteria, such as ATP production, protein secretion, cell division and vesicles formation, and protein modification pathways (Woese and Fox 1977; Woese et al. 1990; Forterre 1997). Archaea therefore seem to share a strong evolutionary relationship with the Eukarya (Garrett and Klenk 2007; Garrett et al. 2011).

\subsubsection{BIOCOMMUNICATION OF VIRUSES}

With drawing our attention now to viruses and their relatives, we seem to move from cellular life to sub-cellular elements. Current knowledge about the virosphere and their roles in evolution ("virolution") indicates interactions of RNA viruses, DNA viruses, viral swarms, and viral and RNA-based subviral networks that co-operate and coordinate (regulate) within cellular genomes either as replication-relevant co-players or suppression-relevant silencers (Ryan 2009; Stedman 2013, 2015; Seligmann and Raoult 2016). Some represent infectionderived modular tools of non-coding RNAs, which have built consortia of complementary agents that function together (Tycowski et al. 2015).

Viruses have long been accepted only as disease-causing, epidemic phenomena, with lytic and therefore extremely dangerous consequences for infected organisms. However, new research has corrected this picture (Villarreal 2009; Witzany 2012b, Berliner et al. 2018). Viruses are part of the living world, in most cases integrated in the cytoplasm or the nucleoplasm of cells, without harming the host. Viruses are on their way to representing the best examples of symbiotic relation-

AQ 19 ships, because there is no (!) living being since the start of life that has not been colonized by them, in most often cases in the form of multiple colonizations (Villarreal 2005).

Today, we can identify several key players that coordinate and organize the genetic content compositions of host organisms (Koonin 2016). They include endogenous viruses and defectives, transposons, retrotransposons, long terminal repeats, non-long terminal repeats, long interspersed nuclear elements, short interspersed nuclear elements, group I introns, group II introns, phages, and plasmids (Weiner 2006; Jurka et al. 2007; Slotkin and Martienssen 2007; Lambowitz and
Zimmerly 2011; McNeil et al. 2016; Belfort 2017). These are just some examples that use genomic DNA as their preferred living habitat. This means that DNA is not a solely stable genetic storage medium that serves as an evolutionary protocol but is also a species-specific ecological niche for viral RNAs.

Persistent viral lifestyle is the most dominant biological lifestyle on this planet (Villarreal 2005). From this perspective, the total number of cellular organisms looks like small islands in an ocean of the global virosphere. Viruses and virusderived parts represent the most abundant genetic information on the planet, overrepresenting cellular genetic information 10 times. If we only consider prokaryotic life, we have a number of prokaryote viruses (phages) of $10^{31}$, which means if we line up the length of their virions, we get 40 million lightyears (Rohwer et al. 2014). Importantly, a key feature of this viral lifestyle is that only few need to remain as functional agents, such as mammalian endogenous retroviruses needed for the syncytia, which regulate mammalian pregnancy (Perot et al. 2012), not to forget the role of persistent viruses in any kind of host immunity functions.

In most cases, parts of infectious agents remain as defec- AQ 21 tives some known as LTRs, non-LTRs, SINEs, LINEs, and Alu's, which are later on co-adapted for cellular needs such as regulation tools in all steps and fine-tuned substeps of cellular functions, such as transcription, translation, epigenetics, repair, and immunity (Slotkin and Martienssen 2007; Lambowitz and Zimmerly 2011; Witzany 2011b; Chalopin et al. 2012; Conley and Jordan 2012; Roossinck 2015).

The abundance of such genetic agents has been identified during the last 40 years as obligate inhabitants of all genomes, whether prokaryotic or eukaryotic. They infect, insert, and delete; some cut and paste; others copy and paste; and both spread within the genome. They change host genetic identities by insertion, recombination, or epigenetic regulation or re-regulation of genetic content, and co-evolve with the host to interact in a modular manner (Geuking et al. 2009; Shapiro 2011). Together with non-coding RNAs, they shape both genome architecture and regulation. In this respect, they are the agents of change, not only over evolutionary time but also in real time as domesticated agents.

Viruses can co-operate, that is, they interact to build groups that invade host genomes and even compete as a group for limited resources such as host genomes (Villarreal and Witzany 2013a, 2013b). This leads to an extraordinary effective result and a key behavioral motif that is able to integrate a persistent lifestyle into cellular host organisms, the "addiction" modules: former competing viral groups are counterbalancing each other, together with the host immune system (Villarreal 2012a). Although rather stable under certain circumstances, this addiction balance can also get out of balance, which means the competing viral features may become virulent again. But when stable, we can find such counter-regulating paired genes of the addiction modules, as in the restriction/modulation (RM) systems as well as in the toxin/antitoxin (TA) systems (Harms et al. 2018). Insertion/deletion functions represent similar modules as do the RM systems. This "infectious" 
colonization by new addiction modules is a main process in generating new sequence space without error replication and therefore in the evolution, conservation, and plasticity of host genetic identities. In this perspective, the genetic identities of cellular life throughout all domains of life are edited by their genetic parasites.

More recently, it has been found that phages communicate to decide whether to initiate lysogeny or not. Some phages produce communication peptides that are released. In subsequent infections, progeny phages measure the concentration of this peptide and lysogenize if the concentration is high. Interestingly, different phages encode different versions of the communication peptide, representing a phage-specific peptide communication code for lysogeny decisions (Erez et al. 2017). Virus-to-virus interactional motifs generally range from conflict to co-operation in various forms dependent on situational context (Díaz-Muñoz et al. 2017).

Consequently, the biocommunication approach has to integrate coherent natural genome editing of the genetic code by viruses (Witzany 2009). In this perspective, the genetic code of living organisms did not result out of chance mutations (error-replication events) that are biologically selected. The error-replication narrative has problems to explain the sudden emergence of new species, new phenotypic traits, and genome innovations as a sudden single event.

\subsubsection{BIOCOMMUNICATION OF RNA STEM-LOOP GROUPS}

To go one step deeper to the roots of life, we meet the viroids, short strands of circular, single-stranded RNA virus without a protein coat (Flores et al. 2012, 2014; Diener 2016). Here, we are only at the RNA strand level, which clearly shows infective and host-manipulating properties. This fits into the RNA world of RNA stem-loop groups, RNA group identities, and selection relevant biotic behavior (Robertson and Joyce 2012; Lehman 2015).

Recently, it has been found that single stem loops interact in a purely physical-chemical mode, without selective forces (Hayden and Lehman 2006; Smit et al. 2006). But if these single RNA stem loops build groups, they transcend the purely physical-chemical interaction pattern and emerge biological selection, biological identities of self/non-self identification and preclusion, and immune functions, dynamically varying (adapting) their membership roles (Marraffini and Sontheimer 2010; Vaidya et al. 2013; Krupovic and Koonin 2016).

A single alteration in a base-pairing RNA stem that leads to a new bulge may dynamically alter not just this single stemloop but also the whole group identity of which this stem loop is part (Villarreal and Witzany 2013a, 2013b). Simple selfligating RNA stem loops can build much larger groups of RNA stem loops that serve to increase complexity (Briones et al. 2009; Gwiazda et al. 2012). This may lead to ribozymatic consortia, which later on build success stories, such as (1) the merger of the two subunits of transfer RNAs, (2) RNAdependent RNA polymerases for replication of RNA through AQ 22 RNA, and (3) the subunits of ribosomal RNAs, all of them groups that evolved and functioned for different reasons than in the later conserved modes (Dick and Schamel 1995; Sun and Caetano-Anolles 2008; Fujishima and Kanai 2014; Kanai 2015).

The RNA stem-loop groups not only generate and constitute nucleotide sequences that serve as information storage media but also primarily interact (Nicholson and White 2014). The generation of RNA stem-loop consortia results in real entities, not just genetic syntax, and they are active in contributing to the identity of such groups and rejecting agents that do not fit in this identity. In several motifs, the interactions depend on the context in which an interaction takes place (Doudna et al. 1989; Przybilski and Hammann 2007; Popovic et al. 2015). This may be evolutionary conserved in DNA, as demonstrated in the co-operative behavior of the two ribosomal subunits. The activity is crucial for the result of cooperation (Doudna and Rath 2002).

Significantly, mixtures of RNA fragments that self-ligate into self-replicating ribozymes spontaneously form co-operative networks (Robertson and Joyce 2014). For example, threemember networks show highly co-operative growth dynamics. When such co-operative networks compete directly against selfish autocatalytic cycles, the former grow faster, indicating the ability of RNA populations to evolve greater complexity through co-operation (Vaidya 2012; Vaidya et al. 2012). In this respect, co-operation clearly outcompetes selfishness. Therefore, the primacy of selfish gene hypothesis is outdated on the RNA level.

RNA groups are able to act as de novo producers of nucleic acid sequences, identify sequence-specific target sites, coherently integrate such sequences into pre-existing ones (without destruction of former content arrangements), recombine according to adaptational needs, and mark sequence sites to vary meaning epigentically or identify sequences to be marked for excision or deletion (Bushman 2003; Martinez et al. 2017). In all these processes, the genetic identity of the genetic parasite and/or the host genome may vary, with far-reaching consequences in terms of the function, co-operation, and coordination of various regulatory networks. Natural genome editing is therefore far from being a random-like process as a result of error replication (mutations).

Non-coding RNAs interact with DNA, RNA, and proteins and play important roles in nuclear organization, transcription, posttranscriptional, and epigenetic processes (Zuckerkandl and Cavalli 2007; Mattick 2009; Mercer and Mattick 2013). Non-coding RNAs are transcribed in both the sense and antisense directions and may be expressed in a cell type, subcellular compartment, developmental stage, or an environmental stimuli-specific, that is, context-dependent, manner (Zinad et al. 2017). Specific RNA polymerases overlap in transcriptional contents, which means that each nucleotide can participate in varying transcriptional content arrangements according to varying contexts (Mattick 2010, 2011).

Non-coding RNAs can be regulated in a varying manner, coordinated or independently, autonomously or functionally interrelated, and can regulate individual genes as well as large genetic networks; they can precisely control the spatiotemporal 
deployment of genes that are executing neuronal processes with extreme cell specificity (Bartel 2004; Matera et al. 2007). Various classes of non-coding RNAs target each other for post-transcriptional regulation via alternative splicing, polyadenylation, 5' capping, non-templated modifications, and RNA editing. RNA editing especially can transmit environmental information to the epigenome and therefore enable neuronal plasticity with learning and memory (Kandel 2001;

AQ 23 Qureshi and Mehler, 2012). Additionally, non-coding RNAs can undergo nuclear-cytoplasmic, nuclear-mitochondrial, and axodendritic trafficking via ribonucleoprotein complexes that promote the spatiotemporal distribution and function of various combinations of ncRNAs, mRNAs, and RNA-binding proteins (Clark et al. 2013; Mercer and Mattick 2013).

If we think of biocommunication as sign-mediated interaction, the question arises what are the signs used in RNA stem-loop interactions? RNAs themselves represent signs as

AQ 24 their four bases of the RNA alphabet. In this non-cellular interacting agents the interaction binding sites are the bases themselves to be identified as identity-indices being relevant as information tools for interactional motifs such as integration or preclusion (self and non-self differentiation).

\subsubsection{COMMUNICATION AT THE ORIGIN OF LIFE}

How did prebiotic chemistry start life? From the biocommunication approach, there is a variety of RNA agents that share the competence to act on nucleic acid sequences (genetic

AQ 25 code) by several techniques, such as de novo generation, ligation/degradation, insertion/deletion, silencing, amplification, epigenetic markings, editing, splicing, and kissing. This is in tune with the general assumption that no natural code codes itself but needs a consortium of competent agents that act on this code (Witzany 2011b, 2012, 2014b; Witzany and Baluška, 2012). Now, we can ask how these agent consortia evolve and how they interact, co-operate, or compete, or even both, at different times, depending on the varying real-life contexts.

\subsubsection{From "Dead" to "Living" by SOCIAL INTERACting RNAs}

It has been suggested that a "dead" state controlled by prebiotic chemistry and a "living" state controlled by autocatalytic replication should be differentiated (Higgs and Lehman 2014).

Recent empirical data and experiments demonstrated that single RNA stem loops react only in a physical-chemical way according to natural laws, without any biotic feature assembling a "dead" state clearly. If we have a group of RNA-set loops that interact and initiate group building, biological selection emerges, which resembles a "living" state (Vaidya 2012).

Also import is the fact that co-operative RNA stem loops AQ 26 outcompete selfish agents.

From the biocommunication approach, the autocatalytic set narrative of Stuart Kauffman looks rather coherent, because it represents a kind of social interaction. Unfortunately, the autocatalytic set concept reduces behavioral motifs to an explanatory model of systems theory, that is, the interacting RNA stem loops as a "system" that functions according to mathematical (formalizable) features. As we have seen in the introduction, behavioral motifs of interacting living agents are not within the expertise of mathematical theories or their derivatives, for several serious reasons (Witzany 1995, 2011a).

Also, the in-between definition of abiotic and biotic features such as "molecular co-operation" does not function as an appropriate explanatory tool, because if we look at biotic co-operation, we deal with living agents that co-operate. RNA "entities" consist of molecules, but molecules in a prebiotic world cannot co-operate like agents representing living organisms that co-operate based on communicative interactions, which is absent in abiotic matter. Molecules in a prebiotic world only react strictly according to physical/ chemical laws. No biological selection is present here.

The reaction between single-stranded RNAs and their fold-back capability to form double strands (stems), including single-stranded regions (loops), that are free to interact in cis (kissing loop to increase complex functional motifs) and trans (integration or warding of infectious non-self agents) are based on a physical/chemical feature (complementary base pairing). Although their biotic interactions depend on complementary base pairing, they overrule physical/chemical laws by their biotic behavior such as biological selection, group building, group identity, and self/non-self differentiation, all of which are absent in abiotic planets.

In RNA groups that interact on identity motifs such as integration or warding off and self and/or non-self RNAs, the RNAs represent living agents underlying biological selection. This phenomenon is clearly absent in abiotic planets. The primary goal is the interaction becoming part of co-operative networks that may also be competing and restricting (Popovic et al. 2015), as documented in the predominant ligase function, in contrast to the nuclease function (Hayden and Lehman 2006; Díaz Arenas and Lehman 2010). This means the turn to life is also a behavioral pattern between becoming part of an identity of RNA groups that reject those that do not fit into this identity. The unique aspect of such RNA stem loops is that they may act both as templates for replication and as catalysts, if they are spatially separated.

\subsubsection{The Origin of RNA Group Identity and the Origin as a Genetic Code}

Humans consist of molecules. Yes, we need an abundance of oxygen atoms (that we call air) to transport vocal sound and talk to each other to organize everyday life. But this does not help us understand human language and communication. Detailed investigations and measurements of the molecular movements of oxygen atoms when humans talk to each other do not tell us anything about intentions being expressed by several different behavioral motifs.

If the interactions of individual RNA stem loops lead to groups of RNA consortia, we can look at the crucial event 
of them becoming more than physics and chemistry, which determine abiotic planets exclusively. The group interactions of RNA stem loops make the genotype evolve into semiotic biology, which means the emergence of natural code rules (syntax, pragmatics, and semantics). The characters get their natural language-like feature only through the social inter-

AQ 27 actions of RNAs. Because the interactions not only combine physical-chemical parts but also nucleotides, they have an inherent opportunity to serve as semiotic signs and as characters for a language/code-like property, which represent information about RNA-group identities. Although statistically measurable, this semiotic feature cannot be substantiated by quantifiable analyses, because it is a socially interacting feature (Witzany 2016).

All such interactions depend on the ability to identify appropriate interaction partners and therefore differentiate between self and non-self, which means differentiating identity-sharing agents against proponents, which represent non-identity and must be fought, precluded, and warded off (Marraffini and Sontheimer 2010). Others may represent cooperation partners; some are actually interaction partners. Others remain as silenced enemies, which could destroy identity. Importantly, later on, in another context, they may be useful tools for co-opting or ex-apting processes. At different times, formerly fought non-identity proponents may be useful tools for generating new partnership (Villarreal 2011, 2012a, 2012b, 2015, 2016).

Several DNA- and RNA-degrading processes are not investigated under the assumption that they serve as useful resources for re-use and identity-building modules (Vaidya et al. 2013; Villarreal 2015, 2016). Additionally, important and key features of this agent-based co-operativity are the fastchanging identities, which lead to the question of how a former enemy becomes a new co-operation partner. What does this mean for former co-operative partners, which may turn into enemies, in fast-changing functional partnerships and the concurrent changes in organization and syntax order? These interaction processes start from the beginning of RNA life (Hayden and Lehman 2006; Mattick 2011; Yarus 2011; Higgs and Wu 2012; Higgs and Lehman 2015), that is, life without unicellular organism. But group identity and co-operativity of an RNA collective also require opposite functions for the genesis of life (social behavior of agents). This is an essential part of the "gangen hypothesis," which describes RNA groups emerging and acting like gangs (Villarreal 2015) in the context of the virosphere and the world of cell-based organisms.

The genetic code with its typical language-like features, that is, characters assembled according to syntactic, pragmatic, and semantic (combinatorial, context-dependent, and contentcoherent) rules, takes the stage of a real, natural language, with the interactional group building of various RNA stem loops. The interactional and group-building co-operativity of the RNA stem loops constitutes the genetic code as a real natural code, not its physico-chemical key characters alone.

The crucial difference of the biocommunication perspective to that of molecular biology is that it is not the molecular aspect solely, but the agent-groups' aspect. The RNA stem loops are part of a group identity, which co-operates or precludes and, by compartmentalization, gets the same first stages of conservation. Until DNA was invented-reverse transcriptase is the most appropriate candidate for this-conservation would have been a rare event, instead of being a constantly evolutionary innovation process of maximum productivity of genetic novelties (Witzany 2008; Moelling et al. 2017). Too much productivity in former concepts has been termed "error catastrophe." Pure physico-chemical variations based on replication are correctly termed error. In a social RNA perspective as the biocommunication approach, this is not an error but productivity of novelties. The paradigmatic differences between the concepts of molecular biology and the biocommunication approach are shown in Table 2.4.1.

\subsubsection{Repetitive Sequence Syntax is Essential IN RNA COMmUNication}

The repetitive syntax comprises the main characteristics of nucleotide sequences that represent interactions of RNA stem loops (Shapiro and Sternberg 2005). Stem-loop group building is and was based on repeat syntax and the complementary binding rules of the four bases of the RNA alphabet. Also,

\section{TABLE 2.4.1}

\section{Different Paradigms Investigating and Defining Life}

$\begin{array}{lll}\text { Key Terms } & \text { Molecular Biology } & \text { Biocommunication } \\ \text { "Dead" } & \text { Pre-biotic chemical } & \text { No sign-mediated } \\ \text { reactions } & \text { interactions } \\ \text { "Living" } & \begin{array}{c}\text { Replication/ } \\ \text { biological selection } \\ \text { (molecular }\end{array} & \begin{array}{c}\text { interactions } \\ \text { (social events) }\end{array} \\ & \text { reactions) } & \\ \text { Natural laws } & \text { Semiotic rules } \\ \text { RNA- } & \text { Molecular } & \text { Identity-groups } \\ \text { ensembles } & \text { co-operation } & \text { integrate or preclude } \\ & \text { non-self agents } \\ \text { Viruses } & \text { Escaped selfish } & \text { Essential agents of all } \\ & \text { parasites } & \text { life } \\ \text { Biological } & \text { Fittest type } & \text { Fittest consortium } \\ \text { selection } & & \\ \text { Genetic code } & \text { Genetic material } & \text { Genetic text } \\ & & \text { (according syntax, } \\ & & \text { pragmatics, } \\ & & \text { semantics) } \\ \text { Communication } & \text { Information transfer } & \text { Social interactions } \\ & \text { (via coding/ } & \text { (of agent-groups } \\ & \text { decoding } & \text { mediated by signs } \\ & \text { mechanisms) } & \text { according semiotic } \\ & & \text { rules) }\end{array}$

The molecular biological paradigm explains life by the physical-chemical and information theoretical (mathematical theory of language) properties of living organisms and life processes; the biocommunication approach explains life as a social event of cellular and sub-cellular agents that communicate, that is, based on interactions that are sign-mediated according to three levels of semiotic rules. 
the modifications on RNA sequences-after being transcribed out of DNA storage medium, such as loop kissing, RNA editing, splicing, and others-depend on repetitive syntax (Witzany 2017b). The non-repetitive syntax - main characteristics of protein-coding sequences-represents another code, an evolutionarily later-derived code for DNA storage of protein blueprints, not relevant for social RNA interactions such as group building, recognition (identifying), attack, and defense against genetic parasites (which rely also on repetitive sequence order). The main reason is that repetitive syntax represents a recognition pattern completely different from non-repetitive ones (Jurka et al. 2007). If an invading RNA species meets a host genome, it will sense and use repetitive sequences, which are much easier for insertion than nonrepetitive ones. This is why genetic parasites insert more into

AQ 28 non-coding repetitive syntax structures than in protein-coding non-repetitive syntax structures. This means that insertions with relevant evolutionary drive are inserted into regulationrelevant genome space, not in protein body-coding regions.

\subsubsection{DNA Sequence Syntax with Variable Meanings}

Consequently, the biocommunication approach has to integrate coherent natural genome editing of the genetic code of living organisms. In this perspective, the genetic code of living organisms cannot be the result of chance mutations (error-replication events) that are biologically selected. The error-replication narrative has serious problems to explain the sudden emergence of new species, new phenotypic traits, and genome innovations as a sudden single event.

The genetic syntax, that is, the nucleotide arrangement of genetic information, is not unequivocal. This means that a given genetic sequence does not offer its final meaning. There are several processual steps in which the same sequence syntax may get several different meanings (functions). In natural languages and codes, this is a usual procedure andadditionally - it saves energy costs: A given sign sequence may represent various meanings/functions according its contextual use. It is not necessary to generate a new sequence for every function. This indicates the primacy of pragmatics in determining the sequence structure, not its syntax (Doudna et al. 1989; Cech 2012; Witzany 2014b). Several contextdependent natural modifications of the meaning (function) of a given DNA sequence are currently known and investigated. Let's have a look at the various techniques to modify meaning (function) of given genetic sequences.

The currently known natural processes of generating variable natural meaning functions out of a given DNA sequence are the context-dependent markings in epigenetics, which also play a key role to understand and coherently explain memory and learning as competencies of living organisms in all domains of life (Witzany 2018). Additionally, we may think of complex regulatory control via RNA editing, alternative splicing, the various roles of tRNA-derived fragments, ribosomal frameshifting, the interaction motif of kissing loops, bypassing, translation, the role of competing endogenous
RNAs, and diversity-generating retroelements, not to forget pseudoknotting (Maizels and Weiner 1994; Keam and Hutvagner 2015; Arkhipova 2017; Yablonovitch et al. 2017).

Most interestingly, the base pairing in pseudoknots tends to be strictly context-sensitive, and base pairing overlaps in sequence positions. Additionally, the emergence of singlenucleotide bulge loops can hardly be predicted. This currently places limitations on algorithm-based prediction models, such as dynamic programming, and on stochastic context-free grammars (Lyngs $\varnothing$ and Pedersen 2004). It indicates the language/code nature of nucleic acid language, which represents the possibility of coherent de novo generation and contextdependent alterations for a diversity of different meanings (functions) relating to the same syntax structures.

All these natural techniques fulfilled by RNA consortia must be mentioned if we think about artificially manipulating genes of living organisms. Without these historically evolved interwoven interaction networks, the natural competence of gene conservation cannot be understood coherently. Genes and their regulatory networks are not at all molecular bricks that can be combined and divided in a lego-like manner. If synthetic biology tries to generate living organisms artificially, it should be sure to guarantee the whole network coherence. Otherwise, low-level manipulation will be the result and may cause far-reaching ethical problems, which are not within the expertise of natural sciences in general.

\subsubsection{CONCLUSIONS}

If we look at life in contrast to abiotic matter, we will identify cellular organisms that coordinate and organize their life actively by communicative actions, which means that they use signs in various forms to interact. The use of signs is essential. The sign use is governed by three levels of rules: how to combine signs to sign sequences for more complex information (syntax); the context dependence, which determines meaning of the used sign sequence (pragmatics); and content coherence, in which signs are used to designate something (semantics). All communication processes in the cellular world share these features.

If we go a step deeper, communication forms change dramatically. In the RNA world, the evolutionary produced sign sequences, which we would term a kind of "writing down" what happened (as evolutionary protocol), are a side result of constant interacting RNAs, stabilizing their functional forms by proteins. The communication in the RNA world is a different one to that of the cellular world, another essential level. Communicating RNAs share common motifs to reach their goals, described earlier. The signs in this form of communication are the interacting agents themselves, as they represent a natural code alphabet of four nucleotides, which are combined according to semiotic rules coherent with the physical chemical structures. The interacting RNAs resemble both a syntax like alphabetic order, dominated by repeat sequences, and context-dependent interaction that represent (and are the result of) biological selection, which is absent in abiotic matter. The RNAs serve as editors of RNA sequence only 
by their group interactions, which lead to group identities. Competing RNA group identities initiate biological selection. Several smaller RNA groups may be combined to form bigger elements such as tRNA and even ribosome and other RNPs with essential functions in all life, as they serve as crucial tools for gene regulation in transcription, translation, repair,

AQ 29 immunity, inheritance, etc. in any known cellular organism.

The very vivid and highly active meeting place of these two levels of communication, (1) cellular sign-mediated interactions and (2) RNA stem-loop group interactions, are (3) competent viruses or, better, the virospheres, which use both communication systems, perfectly adapted to the whole life on this planet. They are the driving force of life based on (a) RNA world communication and (b) cellular communication, which can be edited by viruses in an abundance of ways. As masters of the technique of natural genome editing in all the cellular world, they do not need a cell-independent replication. Interestingly, they do not damage cellular life during persistent integration but serve as the key for all forms of immunity for their host organisms constantly adapting to the high productivity of viruses. They serve as key, based on the RNA world communication, which they use actively for their tremendous repertoire of techniques to invade, manipulate, and regulate cellular life forms. Together, these three agent-based lifeworlds, RNA world, virosphere, and cellular organisms, constitute life as we know it. We may come closer to understand the secret of life now, if we do not take life mechanistically again.

\section{REFERENCES}

Arkhipova, I.R. 2017. Using bioinformatic and phylogenetic approaches to classify transposable elements and understand their complex evolutionary histories. Mob. DNA. 8: 19.

Austin, J.L. 1975. How to Do Things with Words. London, UK: Harvard University Press.

Bais, H.P., Park, S.W., Weir, T.L. et al. 2004. How plants communicate using the underground information superhighway. Trends Plant Sci. 9: 26-32.

Baluska, F., Mancuso, S., and D. Volkmann (Eds.). 2006. Communication in Plants. Heidelberg, Germany: Springer.

Bartel, D.P. 2004. MicroRNAs: Genomics, biogenesis, mechanism, and function. Cell 116: 281-297.

Bassler, B.L. 1999. How bacteria talk to each other: Regulation of gene expression by quorum sensing. Curr. Opin. Microbiol. 2: 582-587.

Belfort, M. 2017. Mobile self-splicing introns and inteins as environmental sensors. Curr. Opin. Microbiol. 38: 51-58.

Ben Jacob, E., Becker, I., Shapira, Y., and H. Levine. 2004. Bacterial linguistic communication and social intelligence. Trends Microbiol. 12: 366-372.

Berliner, A., Mochizuki, T., and K.M. Stedman. 2018. Astrovirology: Viruses at large in the universe. Astrobiology 18: 207-223.

Blande, J.D., and R. Glinwood (Eds.). 2016. Deciphering Chemical Language of Plant Communication. Cham, Switzerland: Springer.

Bohn, M., Call, J., and M. Tomasello. 2015. Communication about absent entities in great apes and human infants. Cognition 145: 63-72.
Bohn, M., Call, J., and M. Tomasello. 2016. The role of past interactions in great apes' communication about absent entities. J. Comp. Psychol. 130: 351-357.

Brenner, S. 2012. Turing centenary: Life's code script. Nature 482: 461. Briones, C., Stich, M., and S.C. Manrubia. 2009. The dawn of the RNA world: Toward functional complexity through ligation of random RNA oligomers. RNA 15: 743-749.

Bushman, F.D. 2003. Targeting survival: Integration site selection by retroviruses and LTR-retrotransposons. Cell 115: 135-138.

Carnap, R. 1939. Foundations of Logic and Mathematics. Chicago, IL: University of Chicago Press.

Casselman, A. 2007. Strange but true: The largest organism on earth is a fungus. Scientific American, October 4.

Cech, T.R. 2012. The RNA worlds in context. Cold Spring Harb. Perspect. Biol. 4(7): a006742.

Chalopin, D., Tomaszkiewicz, M., Galians, D., and J.N. Volff. 2012. LTR retroelement-derived protein-coding genes and vertebrate evolution. In Viruses: Essential Agents of Life, G. Witzany (Ed.), pp. 269-282. Dordrecht, the Netherlands: Springer.

Chomsky, N. 1964. Current Issues in Linguistic Theory. London, UK: The Hague, Mouton.

Chomsky, N. 1965. Aspects of the Theory of Syntax. Cambridge, MA: MIT Press.

Clark, M.B., Choudhary, A., Smith, M.A. et al. 2013. The dark matter rises: The expanding world of regulatory RNAs. Essays Biochem. 54: 1-16.

Conley, A.B., and I.K. Jordan. 2012. Endogenous retroviruses and the epigenome. In Viruses: Essential Agents of Life, G. Witzany (Ed.), pp. 309-323. Dordrecht, the Netherlands: Springer.

Crespi, B.J. 2001. The evolution of social behavior in microorganisms. Trends Ecol. Evol. 16: 178-183.

Crick, F.H., Griffith, J.S., and L.E. Orgel. 1957. Codes without commas. Proc. Natl. Acad. Sci. U S A. 43: 416-421.

Díaz Arenas, C., and N. Lehman. 2010. Quasispecies-like behavior observed in catalytic RNA populations evolving in a test tube. BMC Evol. Biol. 10: 80

Díaz-Muñoz, S.L., Sanjuán, R., and S. West. 2017. Sociovirology: Conflict, cooperation, and communication among viruses. Cell Host Microbe. 22: 437-441.

Dick, T.P., and W.A. Schamel. 1995. Molecular evolution of transfer RNA from two precursor hairpins: implications for the origin of protein synthesis. J. Mol. Evol. 41: 1-9.

Diener, T.O. 2016. Viroids: "living fossils" of primordial RNAs? Bio Direct. 11: 15.

Dohlman, H.G., and J.E. Slessareva. 2006. Pheromone signaling pathways in yeast. Sci. Signal. 364: cm6.

Doudna, J.A., Cormack, B.P., and J.W. Szostak. 1989. RNA structure, not sequence, determines the 5'splice-site specificity of a group I intron. Proc. Natl. Acad. Sci. U. S. A. 86: 7402-7406.

Doudna, J.A., and V.L. Rath. 2002. Structure and function of the eukaryotic ribosome: The next frontier. Cell 109: 153-156.

Dunn, A.K., and J. Handelsman. 2002. Toward an understanding of microbial communities through analysis of communication networks. Antonie van Leeuwenhoek 81: 565-574.

Eigen, M. 2013. From Strange Simplicity to Complex Familiarity a Treatise on Matter, Information, Life, and Thought. Oxford, UK: Oxford University Press.

Engelmann, J.M., Clift, J.B., Herrmann, E., and M. Tomasello. 2017. Social disappointment explains chimpanzees' behaviour in the inequity aversion task. Proc. Biol. Sci. 284(1861): 20171502. 
Erez, Z., Steinberger-Levy, I., Shamir, M. et al. 2017. Communication between viruses guides lysis-lysogeny decisions. Nature 541: 488-493.

Fernandes, L., Araujo, M.A.M., Amaral, A. et al. 2005. Cell signaling pathways in Paracoccidioides brasiliensis - inferred from comparisons with other fungi. Genet. Mol. Res. 4: 216-231.

Flores, R., Gago-Zachert, S., Serra, P. et al. 2014. Viroids: Survivors from the RNA world? Annu. Rev. Microbiol. 68: 395-414.

Flores, R., Serra, P., Minoia, S. et al. 2012. Viroids: From genotype to phenotype just relying on RNA sequence and structural motifs. Front. Microbiol. 3: 217.

Forterre, P. 1997. Archaea: What can we learn from their sequences? Curr. Opin. Genet. Dev. 7: 764-770.

AQ 30 Frisch, K.V. 1971. Bees: Their Vision, Chemical Senses and Language. Ithaca, NY: Cornell University Press.

Fujishima, K., and A. Kanai. 2014. tRNA gene diversity in the three domains of life. Front. Genet. 5: 142.

Fuqua, C., Winans, S.C., and E.P. Greenberg. 1996. Census and consensus in bacterial ecosystems: The LuxR-LuxI family of quorum sensing transcriptional regulators. Ann. Rev. Microbiol. 50: 727-751.

Garrett, R., and H.P. Klenk. 2007. Archaea: Evolution, Physiology, and Molecular Biology. Maiden, MA: Blackwell Publishing.

Garrett, R.A., Vestergaard, G., and S.A. Shah. 2011. Archaeal CRISPR-based immune systems: Exchangeable functional modules. Trends Microbiol. 19: 549-556.

Geuking, M.B., Weber, J., Dewannieux, M. et al. 2009. Recombination of retrotransposon and exogenous RNA virus results in nonretroviral cDNA integration. Science 323: 393-396.

Goedel, K. 1931. Über formal unentscheidbare Sätze der Principia Mathematicaund verwandter Systeme. Monatshefte fur Mathematik und Physik 38: 173-198.

Gwiazda, S., Salomon, K., Appel, B., and S. Muller. 2012. RNA self-ligation: From oligonucleotides to full length ribozymes. Biochimie 94: 1457-1463.

Habermas, J. 1994. Actions, speech acts, linguistically mediated interactions and the lifeworld. In Philosophical Problems Today, G. Floistad (Ed.), Vol. 1, pp. 45-74. Amsterdam, the Netherlands: Kluwer.

AQ 31 Harms, A., Brodersen, D.E., Mitarai, N., and K. Gerdes. 2018 Toxins, targets, and triggers: An overview of toxin-antitoxin biology. Mol. Cell. pii: S1097-2765(18)30003-0.

Hayden, E.J., and N. Lehman. 2006. Self-assembly of a group I intron from inactiveoligonucleotide fragments. Chem. Biol. 13: 909-918.

Heaton, N.S., and B.R. Cullen. 2017. Viruses hijack a long non-coding RNA. Nature. 552: 184-185.

Higgs, P.G., and N. Lehman. 2015. The RNA World: Molecular cooperation at the origins of life. Nat. Rev. Genet. 16: 7-17.

Higgs, P.G., and M. Wu. 2012. The importance of stochastic transitions for the origin of life. Orig. Life Evol. Biosphere 42: 453-457.

Hilbert, D., and P. Bernays. 1934/1939. Grundlagen der Mathematik. Berlin, Germany: Springer.

Inoue, Y., Saga, T., Aikawa, T. et al. 2017. Complete fusion of a transposon and herpesvirus created the Teratorn mobile element in medaka fish. Nat. Commun. 8(1): 551.

Jurka, J., Kapitanov, V.V., Kohany, O., and M.V. Jurka. 2007. Repetitive sequences in complex genomes: Structure and evolution. Annu. Rev. Genomics Hum. Genet. 8: 241-259.

Kanai, A. 2015. Disrupted tRNA Genes and tRNA Fragments: A Perspective on tRNA Gene Evolution. Life (Basel). 5: 321-331.

Kandel, E.R. 2001. The molecular biology of memory storage. A dialogue between genes and synapses. Science 294: 1030-1038.
Kaiser, D., and R. Losick. 1993. How and why bacteria talk to each other. Cell 73: 873-885.

Keam, S.P., and G. Hutvagner. 2015. tRNA-derived fragments (tRFs): Emerging new roles for an ancient RNA in the regulation of gene expression. Life (Basel). 5: 1638-1651.

Kolenbrander, P.E., Andersen, R.N., Blehert, D.S. et al. 2002. Communication among oral bacteria. Microbiol. Mol. Biol. Rev. 66: 486-505.

Koonin, E.V. 2016. Viruses and mobile elements as drivers of evolutionary transitions. Philos. Trans. R. Soc. Lond. B Biol. Sci. 371(1701): 20150442

Krupovic, M., and E.V. Koonin. 2016. Self-synthesizing transposons: Unexpected key players in the evolution of viruses and defense systems. Curr. Opin. Microbiol. 31: 25-33.

Lambowitz, A.M., and S. Zimmerly. 2011. Group II introns: Mobile ribozymes that invade DNA. Cold Spring Harb. Perspect. Biol. 3(8): a003616.

Leeder, A.C., Palma-Guerrero, J., and N.L. Glass. 2011. The social network: Deciphering fungal language. Nat. Rev. Microbiol. 9: 440-451

Lehman, N. 2015. The RNA world: 4,000,000,050 years old. Life (Basel) 5: 1583-1586.

Losick, R., and D. Kaiser. 1997. Why and how bacteria communicate. Sci. Am. 2: 52-58.

Luporini, P., Vallesi, A., Alimenti, C., and C. Ortenzi. 2006. The cell type-specific signal proteins (pheromones) of protozoan ciliates. Curr. Pharm. Des. 12: 3015-3024.

Luporini, P., Vallesi, A., Miceli, C., and R.A. Bradshaw. 1995. Chemical signaling in ciliates. J. Eukaryot. Microbiol. 42: 208-212.

Lyngsø, R.B., and C.N. Pedersen. 2004. RNA pseudoknot prediction in energy-based models. J. Comput. Biol. 7: 409-427.

Maizels, N., and A.M. Weiner. 1994. Phylogeny from function: Evidence from the molecular fossil record that tRNA originated in replication, not translation. Proc. Natl. Acad. Sci. USA 91: 6729-6734.

Margulis, L. 2004. Serial endosymbiotic theory (SET) and composite individuality. Transition from bacterial to eukaryotic genomes. Microbiol. Today 31: 173-174.

Marraffini, L.A., and E.J. Sontheimer. 2010. Self versus non-self discrimination during CRIPR RNA-directed immunity. Nature 463: 568-571.

Martinez, G., Choudury, S.G., and R.K. Slotkin. 2017. tRNA-derived small RNAs target transposable element transcripts. Nucleic Acids Res. 45: 5142-5152.

Matera, A.G., Terns, M., and M.P. Terns. 2009. Non-coding RNAs: Lessons from the small nuclear and small nucleolar RNAs. Nat. Rev. Mol. Cell Biol. 8: 209-220.

Mattick, J.S. 2010. RNA as a substrate for epigenome-environment interactions: RNA guidance of epigenetic processes and the expansion of RNA editing in animals underpins development, phenotypic plasticity, learning and cognition. Bioessays 32: 548-552.

Mattick, J.S. 2011. The double life of RNA. Biochimie 93(11): viii-ix. McCarthy, T. 1984. Translator's introduction. In The Theory of Communicative Action, p. ix. Boston, MA: Beacon Press.

McNeil, B.A., Semper, C., and S. Zimmerly. 2016. Group II introns: Versatile ribozymes and retroelements. WIRES RNA 7: 341-355.

Mead, G.H. 1934. Mind, Self, and Society. Chicago, IL: The University of Chicago Press.

Mercer, T.R., and J.S. Mattick. 2013. Structure and function of long non-coding RNAs in epigenetic regulation. Nat. Struct. Mol. Biol. 20: 300-307. 
Moelling, K., Broecker, F., Russo, G., and S. Sunagawa. 2017. RNase $\mathrm{H}$ as gene modifier, driver of evolution and antiviral defense. Front. Microbiol. 8: 1745.

Morris, C. 1946. Signs, Language, and Behavior. New York: Prentice Hall.

Nicholson, B.L., and K.A. White. 2014. Functional long-range RNA-RNA interactions inpositive-strand RNA viruses. Nat. Rev. Microbiol. 12: 493-504.

Nowak, M.A., and D.C. Krakauer. 1999. The evolution of language. Proc. Acad. Sci. USA 96: 8023-8033.

Peirce, C.S. 1923. How to make our ideas clear. In Chance, Love, and Logic: Philosophical Essays, R.C. Morris (Ed.), pp. 41-42. New York: Harcourt, Brace and World.

Perot, P., Bolze, P.A., and F. Mallet. 2012. From viruses to genes: Syncytins. In Viruses: Essential Agents of Life, G. Witzany (Ed.), pp. 325-361. Dordrecht, the Netherlands: Springer.

Popovic, M., Fliss, P.S., and M.A. Ditzler. 2015. In vitro evolution of distinct self-cleavingribozymes in diverse environments. Nucleic Acids Res. 43: 7070-7082.

Przybilski, D.M., and C. Hammann. 2007. The tolerance to exchanges of theWatson-Crick base pair in the hammerhead ribozyme core is determined by surrounding elements. RNA 13: $1625-1630$.

Qureshi, I.A., and M.F. Mehler. 2012. Emerging roles of non-coding RNAs in brainevolution, development, plasticity and disease. Nat. Rev. Neurosci. 13: 528-541.

Robertson, M.P., and G.F. Joyce. 2012. The origins of the RNA world. Cold Spring Harb. Perspect. Biol. 4(5): a003608.

Robertson, M.P., and G.F. Joyce. 2014. Highly efficient self-replicating RNA enzymes. Chem. Biol. 21: 238-245.

Rohwer, F., Youle, M., Maughan, H., and N. Hisakawa. 2014. Life in Our Phage World. San Diego, CA: Wholon.

Roossinck, M.J. 2015. Metagenomics of plant and fungal viruses reveals an abundance of persistent lifestyles. Front. Microbiol. 5: $1-3$.

Ryan, F. 2009. Virolution. London, UK: Harper Collins

Schauder, S., and B.L. Bassler. 2001. The languages of bacteria. Genes Dev. 15: 1468-1480.

Schroedinger, E. 1944. What is Life? The Physical Aspect of the Living Cell. London, UK: Cambridge University Press.

Searle, J.R. 1976. Speech Acts. An Essay in the Philosophy of Language. Cambridge, UK: Cambridge University Press

Seligmann, H., and D. Raoult. 2016. Unifying view of stem-loop hairpin RNA as origin of current and ancient parasitic and non-parasitic RNAs, including in giant viruses. Curr. Opin. Microbiol. 31: 1-8.

Shannon, C.E., and W. Weaver. 1949. The Mathematical Theory of Communication. Urbana, IL: University of Illinois Press.

Shapiro, J.A. 2011. Evolution: A View from the 21st Century. New York: Financial Times Prentice Hall.

Shapiro, J.A., and R.V. Sternberg. 2005. Why repetitive DNA is essential to genome function. Biol. Rev. 80: 1-24.

Sharma, A., Sahgal, M., and B.N. Johri. 2003. Microbial communication in the rhizosphere: Operation of quorum sensing. Curr. Sci. 85: 1164-1172.

Slotkin, R.K., and R. Martienssen. 2007. Transposable elements and the epigenetic regulation of the genome. Nat. Rev. Genet. 8: 272-285.

Smit, S., Yarus, M., and R. Knight. 2006. Natural selection is not required to explain universal compositional patterns in rRNA secondary structure categories. RNA 12: 1-14.

Stedman, K. 2013. Mechanisms for RNA capture by ssDNA viruses: Grand theft RNA. J. Mol. Evol. 76: 359-364.
Stedman, K.M. 2015. Deep recombination: RNA and ssDNA virus genes in DNA virus and host genomes. Annu. Rev. Virol. 2: 203-217.

Sun, F.J., and G. Caetano-Anollés. 2008. Transfer RNA and the origins of diversified life. PLoS One 3(7): e2799.

Tomasello, M. 2008. Origins of Human Communication. Cambridge, MA: MIT Press.

Turing, A. 1950. Computing machinery and intelligence. Mind 59: 433-460.

Tycowski, K.T., Guo, Y.E., Lee, N. et al. 2015. Viral noncoding RNAs: More surprises. Genes Dev. 29: 567-584.

Vaidya, N. 2012. Spontaneous cooperative assembly of replicative catalytic RNA systems. Dissertations and Theses. Paper 934. doi:10.15760/etd.934

Vaidya, N., Manapat, M.L., Chen, I.A. et al. 2012. Spontaneous network formation among cooperative RNA replicators. Nature 491: 72-77.

Vaidya, N., Walker, S.I., and N. Lehman. 2013. Recycling of informational units leads to selection of replicators in a prebiotic soup. Chem. Biol. 20: 241-252.

Villarreal, L.P. 2005. Viruses and the Evolution of Life. Washington, DC: ASM Press.

Villarreal, L.P. 2009. Origin of Group Identity: Viruses, Addiction and Cooperation. New York: Springer.

Villarreal, L.P. 2011. Viral ancestors of antiviral systems. Viruses 3: $1933-1958$

Villarreal, L.P. 2012a. The addiction module as social force. In Viruses: Essential Agents of Life, G. Witzany (Ed.), pp. 107-145. Dordrecht, the Netherlands: Springer.

Villarreal, L.P. 2012b. Viruses and Host Evolution: Virus-Mediated Self Identity. Austin, TX: Landes Bioscience and Springer Science+Business Media.

Villarreal, L.P. 2015. Force for ancient and recent life: Viral and stem-loop RNA consortia promote life. Ann. N. Y. Acad. Sci. 1341: 25-34.

Villarreal, L.P. 2016. Viruses and the placenta: the essential virus first view. APMIS 124: 20-30.

Villarreal, L.P., and G. Witzany. 2010. Viruses are essential agents within the roots and stem of the tree of life. J. Theor. Biol. 262: 698-710.

Villarreal, L.P., and G. Witzany. 2013a. The DNA habitat and its RNA inhabitants: At the dawn of RNA sociology. Genomics Insights 6: 1-12.

Villarreal, L.P., and G. Witzany. 2013b. Rethinking quasispecies theory: From fittest type to cooperative consortia. World J. Biol. Chem. 4: 70-79.

Villarreal, L.P., and G. Witzany. 2015. When competing viruses unify: Evolution, conservation, and plasticity of genetic identities. J. Mol. Evol. 80: 305-318.

Villarreal L.P., and G. Witzany. 2018. Editorial: Genome invading RNA-networks. Front. Microbiol. 9: 581.

von Neumann, J. 1966. Theory of Self-Reproducing Automata. Urbana, IL: University of Illinois Press.

Weiner, A.M. 2006. SINEs and LINEs: Troublemakers, saboteurs, benefactors, ancestors. In The RNA World, R.F. Gesteland, T.R. Cech, and J.F. Atkins (Eds.), 3rd ed., pp. 507-534. New York: Cold Spring Harbor Laboratory Press.

Whitehead, A.N., and B. Russell. 1910/1912/1913. Principia Mathematica. Cambridge, UK: Cambridge University Press.

Wiener, N. 1948. Cybernetics, or Control and Communication in the Animal and the Machine. New York: Wiley. 
Witzany, G. 1995. From the "logic of the molecular syntax" to molec ular pragmatism. Explanatory deficits in Manfred Eigen's concept of language and communication. Evol. Cogn. 1: 148-168.

Witzany, G. 2000. Life: The Communicative Structure. Norderstedt, Germany: LoB.

Witzany, G. 2006. Serial endosymbiotic theory (SET): The biosemiotic update. Acta Biotheor. 54: 103-117.

Witzany, G. 2008. The viral origins of telomeres and telomerases and their important role in eukaryogenesis and genome maintenance. Biosemiotics 1: 191-206.

Witzany, G. (Ed.). 2009. Natural Genetic Engineering and Natural Genome Editing. New York: Annals of the New York Academy of Sciences.

Witzany, G. 2010. Biocommunication and Natural Genome Editing. Dordrecht, the Netherlands: Springer.

Witzany, G. 2011a. Can mathematics explain the evolution of human language? Commun. Integr. Biol. 4: 1-5.

Witzany, G. 2011b. The agents of natural genome editing. J. Mol. Cell Biol. 3: 181-189.

Witzany, G. (Ed.). 2011c. Biocommunication in Soil Microorganisms. Heidelberg, Germany: Springer.

Witzany, G. (Ed.). 2012a. Biocommunication of Fungi. Dordrecht, Germany: Springer.

Witzany, G. (Ed.) 2012b. Viruses: Essential Agents of Life. Dordrecht, Germany: Springer.

Witzany, G. (Ed.). 2014a. Biocommunication of Animals. Dordrecht, Germany: Springer.

Witzany, G. 2014b. Language and communication as universal requirements for life. In Astrobiology: An Evolutionary Approach, V. Kolb (Ed.), pp. 349-369, Boca Raton, FL: CRC Press.

Witzany, G. 2015. Life is physics and chemistry and communication. Ann. N.Y. Acad. Sci. 1341: 1-9.

Witzany, G. 2017a. Biocommunication of Archaea. Dordrecht, the Netherlands: Springer.
Witzany, G. 2017b. Two genetic codes: Repetitive syntax for active non-coding RNAs; non-repetitive syntax for the DNA archives. Commun. Integr. Biol. 10(2): e1297352.

Witzany, G. 2018. Evolution of Genetic Information without ErrorReplication. World Scientific (forthcoming).

Witzany, G., and F. Baluška (Eds.). 2012a. Biocommunication of Plants. Heidelberg, Germany: Springer.

Witzany, G., and F. Baluška. 2012b. Life's code script does not code itself. The machine metaphor for living organisms is outdated. EMBO Rep. 13: 1054-1056.

Witzany, G., and M. Nowacki. 2016. Biocommunication of Ciliates. Dordrecht, the Netherlands: Springer.

Wittgenstein, L. 1953. Philosophical Investigations. Oxford, UK: Basil Blackwell.

Woese, C.R., and G.E. Fox. 1977. Phylogenetic structure of the prokaryotic domain: The primary kingdoms. Proc. Natl. Acad. Sci. U S A 74: 5088-5090.

Woese, C.R., Kandler, O., and M.L. Wheelis. 1990. Towards a natural system of organisms: Proposal for the domains Archaea, Bacteria, and Eukarya. Proc. Natl. Acad. Sci. U S A 87: 4576-4579.

Yablonovitch, A.L., Deng, P., Jacobson, D., and J.B. Li. 2017. The evolution and adaptation of A-to-I RNA editing. PLoS Genet. 13(11): e1007064.

Yarus, M. 2011. Life from an RNA World: The Ancestor Within. Cambridge, MA: Harvard University Press.

Yu, R.C., Pesce, C.G., Colman-Lerner, A. et al. 2008. Negative feedback that improves information transmission in yeast signalling. Nature 456: 755-761.

Zinad, H.S., Natasya, I., and A. Werner. 2017. Natural antisense transcripts at the interface between host genome and mobile genetic elements. Front. Microbiol. 8: 2292.

Zuckerkandl, E., and G. Cavalli. 2007. Combinatorial epigenetics, 'junk DNA', and the evolution of complex organisms. Gene 390: 232-242. 